\title{
Auto-organização, complexidade e formação da consciência bioética
}

\author{
Self-organization, complexity and the emergence of bioethical conscience \\ Valdir Gonzalez Paixão Junior* \\ Alfredo Pereira Junior** \\ Enidio Ilario***
}

\begin{abstract}
RESUMO: O presente artigo apresenta os conceitos de auto-organização e autonomia, a partir dos pensamentos de Michel Debrun e Edgar Morin, bem como uma discussão a respeito da formação da consciência bioética no processo educativo escolar. Essa consciência seria em parte o resultado de um processo "hetero-organizativo", partindo de ações do educador que contribuam para o desenvolvimento da autonomia dos educandos e, assim, favoreçam sua auto-organização enquanto "sujeito ético responsável".
\end{abstract}

PALAVRAS-ChaVE: Consciência. Educação. Bioética.

ABSTRACT: This article introduces the concepts of self-organization and autonomy as presented by the thought of Michel Debrun and Edgar Morin and their relationship to the development of a bioethical conscience by means of the school educational process. The proposal aims to contribute to the development of autonomy of students and thus be conducive to their self-organization as "responsible ethical subjects".

KEYWORDS: Conscience. Education. Bioethics.

\section{INTRODUĈ̣̃O}

O presente artigo pretendeu argumentar que o processo de formação da consciência bioética depende tanto de ações hetero-organizativas do educador quanto de ações de promoção da autonomia do educando, ambas podendo contribuir para a auto-organização pessoal do último, dentro de uma perspectiva da complexidade. Nesse sentido, a educação, em particular a escolar, pode contribuir provendo condições e situaçôes para que o próprio indivíduo / aluno se "auto-eco-organize" na construção dessa consciência bioética.

De início, partimos da ideia / conceito de auto-organização. Uma teoria da auto-organização situa-se no plano transdisciplinar, se aplicada a uma ampla variedade de sistemas. O objetivo da construção dessa teoria não é explicar a dinâmica dos sistemas, para o que são elaborados métodos e técnicas próprios de cada área científica específica. O propósito da teoria é o de descrever princípios comuns e possibilitar o entendimento de aspectos comuns da dinâmica dos diversos tipos de sistema.
Em todos os sistemas, há fatores endógenos e exógenos determinantes de sua dinâmica.

Auto-Organização (abreviada AO) e Hetero-Organização são dois tipos compatíveis de dinâmica, em que há, respectivamente, uma preponderância ora de fatores endógenos ora de fatores exógenos ${ }^{1,2}$.

Identificamos alguns aspectos característicos dos sistemas auto-organizados, como os seguintes.

\section{Espontaneidade}

Expressa a existência de uma espontaneidade dos sistemas naturais, artificiais ou humanos. Tal espontaneidade também pode ser entendida como um limite ao controle desses sistemas por parte da razão instrumental.

\section{Respostas Construtivas às Perturbações}

Os sistemas auto-organizados são complexos semiabertos (ou semifechados), que derivam seus padrões de organização das relaçôes internas entre seus componentes.

Perturbaçōes de origem externa podem ser utilizadas construtivamente, deflagrando processos organizacionais.

* Licenciado em Filosofia pela Universidade do Sagrado Coração (USC) e Pedagogia pelo Centro Universitário Claretiano (CEUCLAR). Doutor em Sociologia pela Universidade "Júlio de Mesquita Filho" (UNESP/Araraquara-SP). Mestre em Ciências da Religião pela Universidade Metodista de São Paulo (UMESP). Professor Assistente Doutor do Departamento de Educação do Instituto de Biociências da UNESP campus Botucatu-SP, Brasil. E-mail: valdirpaixao@ibb.unesp.br

** Graduado em Filosofia pela Universidade Federal de Juiz de Fora. Doutor em Lógica e Filosofia da Ciência pela Universidade Estadual de Campinas (UNICAMP). Mestre em Filosofia pela Universidade Federal de Minas Gerais (UFMG). Professor Adjunto do Departamento de Educação do Instituto de Biociências da UNESP/Botucatu. E-mail: apj@ibb.unesp.br

*** Graduado em Medicina pela FCM-UNICAMP. Doutor em Psicologia pela PUCCAMP. Mestre em Filosofia. Professor colaborador da disciplina de bioética da Faculdade

de Ciências Médicas da UNICAMP, Departamento de Saúde Coletiva. E-mail: enidioil@fcm.unicamp.br

Os autores declaram não haver conflitos de interesse. 


\section{Presença de Causalidade Circular}

Os sistemas $\mathrm{AO}$ frequentemente apresentam distintos níveis de organização, os quais travam relações de feedback entre si. Essa característica é ilustrada pelo conceito de "Autopoiese"3. Inspirado no funcionamento celular, esse conceito se refere a uma causalidade circular de genoma e metabolismo (genes instruem a produção das proteínas, que regulam o metabolismo; os produtos deste, por sua vez, regulam a expressão dos genes).

\section{Não linearidade}

Os Sistemas AO apresentam aspectos de não linearidade (desproporção entre magnitude de causas e efeitos no sistema; "efeito borboleta"). Um mecanismo que opera nesses processos é a chamada "Criticalidade Auto-Organizada".

Debrun $^{4,5}$ distingue dois tipos de AO: a) AO Primária: ocorre quando um novo sistema se forma a partir do encontro casual de elementos que pertenciam a outros sistemas. Ex.: origem da vida, origem do Estado; b) AO Secundária: ocorre em um sistema já constituído, quando um novo padrão de organização se forma, a partir das interaçôes entre seus componentes e com o ambiente. Ex.: processo terapêutico, jogo de futebol (para uma abordagem do papel da informação na $\mathrm{AO}$ secundária.

Os conceitos centrais da teoria da auto-organização em Debrun são: a) Da interação entre as partes se gera uma forma global nova no sistema; b) Ao longo do processo ocorrem ajustes das e entre as partes; c) $\mathrm{A} \mathrm{AO}$ não é absoluta; ela coexiste com a Hetero-Organização, que pode inclusive derivar do controle centralizado de um agente interno ao sistema; d) Os sistemas AO desenvolvem uma "hierarquia acavalada", em que os níveis "inferiores" não só são controlados pelos "superiores", mas também os controlam, em uma relação de inter-retro-ação (por exemplo, vide o conceito de Hegemonia em Gramsci).

\section{DISTINÇ̃̃O ENTRE AO E AUTONOMIA EM SISTEMAS COMPLEXOS}

Um complexo (complexus, no sentido de "tecido junto") aparece para Morin ${ }^{6}$ no momento em que elementos diferentes encontram-se como inseparáveis constitutivos de um todo (pensemos nas dimensóes do político, do econômico, do sociológico, do psicológico, do afetivo; nos aspectos físicos, biológicos, sociais, culturais, psíquicos e espirituais que constituem o homo complexus, etc.). Esses elementos são tecidos de forma interdependente, se inter-retroagem. $\mathrm{O}$ pensamento complexo se opõe ao pensamento mutilante:

A complexidade é aquilo que tenta conceber a articulação, a identidade e a diferença de todos esses aspectos, enquanto o pensamento simplificante separa esses diferentes aspectos ou unifica-os por uma redução mutilante (...) a aspiração à complexidade tende para o conhecimento multidimensional (p. 176) ${ }^{7}$.

A complexidade coloca, também, de forma interativa o objeto de conhecimento e seu contexto (e o sujeito cognoscente), as partes e o todo, o todo e as partes e as partes entre si, sendo a união entre a unidade e a multiplicidade, "unitas multiplex" (p. 180) ${ }^{6}$. Ela está indissoluvelmente associada às noções de irredutibilidade, ordem, desordem, sistema, organização, aleatoriedade, incerteza, indeterminação, interação, pensamento multidimensional, unidualidade, entropia, neguentropia, autopoiese, universalidade, localidade e singularidade, inter-retroações, sinergias, desvios, reorientações, distinção, comunicação, autonomia e interdependência.

Dentro dessa perspectiva, coloca-se como imprescindível a necessidade de se rechaçar o espírito redutor (aquele que reduz o conhecimento do complexo a uma das partes e que restringe o complexo ao simples; que oculta o imprevisto, o novo e a invenção), a disjunção (incapacidade de organizar o saber disperso, compartimentado, separado, isolado, especializado) e a falsa racionalidade (racionalização abstrata e unidimensional), em prol de uma "ecologia da ação" que leve em consideração a "complexidade que ela supõe, ou seja, o aleatório, acaso, iniciativa, decisão, inesperado, imprevisto, consciência de derivas e transformaçōes" (p. 199-206) ${ }^{6}$.

No que se refere ao ser humano e à sociedade, aparecem em Morin como unidades complexas e multidimensionais. O ser humano é sincronicamente biológico, psíquico, social, afetivo, emocional, racional. Esse homo complexus apresenta uma tríade em circuito, "cérebro / mente / cultura", em que "a mente é o surgimento do cérebro que suscita a cultura, que não existiria sem o cérebro" (p. 53) ${ }^{8}$. Mas ele apresenta, também, a tríade denominada "bioantropológica", em que aparece o circuito "razão / afeto / pulsão", uma tríade inseparável em que 
as três instâncias são não apenas complementares, mas, também, concorrentes, antagônicas e conflituosas, mantendo, assim, uma relação instável, permutante e rotativa entre si.

Há, ainda, a relação triádica entre o "indivíduo / sociedade / espécie" (p. 54-5) ${ }^{8}$. Nesse sentido, a sociedade vive para o indivíduo, o qual vive para a sociedade; a sociedade e o indivíduo vivem para a espécie, que vive para o indivíduo e para a sociedade. A questão que se coloca é: "como manter o equilíbrio, a harmonia entre esses circuitos / tríades que compõem o homo complexus em sua condição humana?".

Para Morin, o caminho a ser percorrido encontra-se, dentro da perspectiva da complexidade, no processo auto-eco-organizador que todo o sujeito, bem como toda a sociedade, deve desenvolver.

Segundo Morin, a organização relaciona-se àquilo que constitui um sistema a partir de elementos diferentes, sendo uma unidade e uma multiplicidade, ao mesmo tempo, não podendo, sob hipótese qualquer, transformar-se o múltiplo em um, nem o um em múltiplo (p. $180)^{6}$. Nesse ponto, pode-se pensar a organização a partir do princípio hologramático, em que não só a parte está no todo como o todo está na parte, do princípio dialógico, em que os antagonismos aparecem como estimuladores e reguladores, e do princípio da organização recursiva, cujos efeitos e produtos aparecem como necessários à sua própria causação e produção:

Um pensamento de organização que não inclua a relação auto-eco-organizadora, isto é, a relação profunda e íntima com o meio ambiente, que não inclua a relação hologramática entre as partes e o todo, que não inclua o princípio de recursividade, está condenado à mediocridade, à trivialidade, isto é, ao erro (p. $193)^{6}$.

A auto-organização aparece como processo permanente e indissociável de desorganização e reorganização presente na fórmula paradigmática de Morin, seu tetragrama:

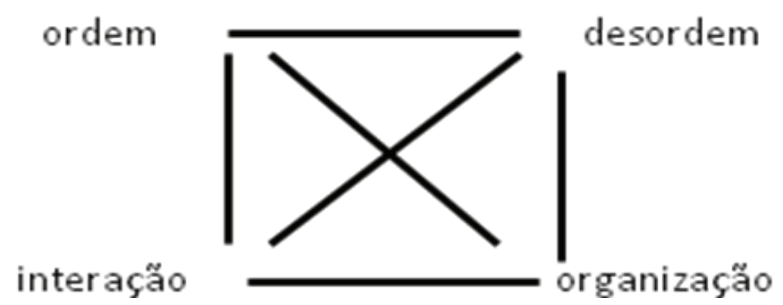

Nenhum dos termos acima pode ser eliminado ou preterido em detrimento do outro. Devemos buscar o "jogo combinatório" e interdependente entre ordem / desordem / interações / organizaçōes.

A necessidade de pensar em conjunto as noções de ordem, de desordem e de organização, na sua complementaridade, concorrência e antagonismo, nos faz respeitar a complexidade física, biológica e humana. Pensar não é só servir às ideias de ordem ou de desordem, é servir-se delas de modo organizador e, às vezes desorganizador, para conceber nossa realidade (p. 197) ${ }^{6}$.

A organização produz tanto a degradação do sistema como a sua própria (entropia), mas, também, a regeneração do sistema, bem como a sua própria regeneração (neguentropia). A entropia participa da neguentropia, que depende da entropia. A autopoiese aponta para essa capacidade dos seres vivos de se reproduzirem a si próprios.

A ideia de autonomia aparece, aqui, ligada ao conceito de sistema, mais precisamente, de sistema aberto em busca de sua regeneração. Um sistema aberto é aquele que se abre energética e, às vezes, informacionalmente para o universo externo, que se alimenta de matéria / energia e informação, segundo Morin (p. 274-5) ${ }^{6}$. É um sistema que pode alimentar sua autonomia, mas mediante a dependência em relação ao meio externo.

Aqui, aparece a ideia de homeostase como propriedade / capacidade indispensável aos sistemas abertos, seres vivos, em especial, de regular o seu ambiente interno em busca de sua estabilidade por meio de ajustes e mecanismos de regulação inter-relacionados.

Nesse sentido, a ideia de autonomia está diretamente relacionada à de dependência. Assim, o conceito de autonomia aparece como relativo e relacional, ou seja, não se pode conceber a autonomia sem a dependência. Assim, em Morin, a auto-organização implica a dependência do mundo externo, sendo uma auto-eco-organização:

A autonomia de que falo não é mais uma liberdade absoluta, emancipada de qualquer dependência, mas uma autonomia que depende de seu meio ambiente, seja ele biológico, cultural ou social. Assim, um ser vivo, para salvaguardar sua autonomia, trabalha, despende energia, e deve, obviamente, abastecer-se de energia em seu meio, do qual depende. Quanto a nós, seres culturais e sociais, só podemos ser autônomos a partir de uma dependência original em relação 
à cultura, em relação à uma língua, em relação a um saber. A autonomia não é possível em termos absolutos, mas em termos relacionais e relativos ( $\mathrm{p}$. $118)^{7}$.

A própria liberdade é vista por Morin não como uma ideia metafísica, mas a partir de uma fundamentação física e biológica relacionada à origem da vida, da mutação genética, da indeterminação microfísica. A liberdade aparece, pois, como o desenvolvimento de uma aptidão auto-organizacional que utiliza a aleatoriedade e a incerteza no sentido de autonomia.

Sintetizando os conceitos de AO e Autonomia de Debrun e Morin, observamos que, embora estejam estritamente relacionados, apresentam algumas diferenças, as quais são de grande importância na perspectiva da prática, uma vez que o educador pode, em suas atividades, contribuir para a autonomia dos educandos, mas não pode promover diretamente sua auto-organização, pois tal tentativa seria, paradoxalmente, uma ação hetero-organizativa.

A auto-organização pessoal seria um processo pelo qual, a partir de açôes desencadeadas por si mesmo, um agente transforma suas condiçōes de vida, superando dificuldades e atualizando potencialidades. Sua força motriz seria o "conatus" espinosiano, traduzido contemporaneamente no conceito de resiliência. É um processo que só ocorre quando o próprio agente se torna protagonista; se conduzido por um agente externo, tratar-se-ia de hetero-organização.

Vale aqui observar que, no campo da Ética e da Bioética, a noção de hetero-organização não deve ser entendida no sentido kantiano de heteronomia, conceito antitético ao de autonomia, daí, na opinião do filósofo de Königsberg, não servir de fundamento para a moralidade. Consideramos que a noção de hetero-organização aqui tratada remete muito mais ao entendimento de Max Scheler, para quem a autonomia se insere em uma comunidade, conforme o autor, uma comunidade de valores, motivo pelo qual é de alguma maneira heterônoma?

Dessa forma, a autonomia diria respeito à capacidade do agente se organizar, podendo ser induzida ou facilitada por um agente externo, como, por exemplo, o profissional da educação. Constitui um dos princípios fundamentais da Bioética, se traduzindo em promoção da liberdade, empoderamento, redução de vulnerabilidades, elaboração e implementação de projetos de vida.

\section{FORMACÃO ESCOLAR E A NECESSIDADE DE FORMAC̣̃̃O DE UMA CONSCIÊNCIA BIOÉTICA}

A formação de uma consciência bioética se faz necessária mediante a formação de sujeitos éticos livres e capazes de deliberar responsavelmente. Esse processo formativo estabelece-se a partir da educação.

Nesse sentido, as instituiçóes sociais, aquelas relacionadas aos espaços de socialização secundária dos indivíduos, têm um papel fundamental e primordial na formação dessa consciência, destacando-se a família, a escola, os meios de comunicação, o Estado, as associações, as ONGs, etc.

Os espaços formativos são plurais e diversificados no tempo presente. Nossa preocupação, no entanto, recai sobre o processo formativo que acontece na escola e como este se relaciona com a formação da consciência bioética de seus alunos.

$\mathrm{Na}$ educação, como apontam Cória-Sabini e Oliveira, "deveria haver um espaço para a formação de um indivíduo crítico, autoconsciente, capaz de promover uma revolução nos valores, pois o autoconhecimento é o começo da liberdade" (p. 54) ${ }^{10}$.

Para Carreras, et al ${ }^{11}$, o objetivo da educação é ajudar o educando a mover-se livremente por um universo de valores, para que aprenda a conhecer, a querer e a inclinar-se para tudo aquilo que for nobre, justo, valioso. Para o autor,

Educar nos valores é educar moralmente, porque são os valores que ensinam o indivíduo a comportar-se como homem, a estabelecer uma hierarquia entre as coisas, a chegar à convicção de que algo importa ou não importa, vale ou não vale, a discernir entre um valor e um contra valor (p. 25) ${ }^{11}$.

Pensamentos autônomos e críticos, capacidade de formulação de juízos de valor, capacidade de decisão em situaçôes distintas, reconhecimento do outro. Todas essas exigências éticas apontam para o sujeito ético, que alcançou a autonomia no desenvolvimento de seu juízo moral ${ }^{12}$ ou que age a partir de uma moral pós-convencional ${ }^{10}$, ou, ainda, que é capaz de, além de respeitar os limites para viver bem e deixar os outros viverem, transpor responsavelmente limites para atingir a maturidade ${ }^{13}$.

Para Carreras, et $\mathrm{al}^{11}$, a escola deve, pois,

Interessar-se e preocupar-se da educação moral que faz parte da educação integral da pessoa, ajudando os alunos e alunas a construir seus próprios critérios, 
permitindo-lhes tomar decisões, para que saibam como enfocar sua vida e como vivê-la e orientá-la (p. 26) ${ }^{11}$.

\section{CONSIDERAÇ̃̃ES FINAIS}

Do exposto nesse artigo, podemos depreender algumas ideais, imprescindíveis para o desenvolvimento de uma consciência bioética: 1. Diante das transformações sócio-política-econômicas e ambientais planetárias, bem como dos desenvolvimentos biotecnocientíficos, há a necessidade premente da formação da consciência bioética de sujeitos éticos responsáveis, que possam criticamente analisar e se posicionar frente a todas essas transformaçôes; 2. No processo de desenvolvimento dessa consciência bioética, há a necessidade de o sujeito depender de fatores exógenos ou hetero-organizativos, os quais estão relacionados à influência do processo educativo que se estabelece em vários espaços, entre os quais o familiar e, em especial, o escolar; 3. Os espaços de formação podem possibilitar condições e situações por meio do processo educativo e de ensino-aprendizagem, para o desenvolvimento da autonomia desse sujeito; 4 . A ação do educador pode favorecer ou desfavorecer a autonomia dos educandos. Nos casos de atitudes paternalistas, assistencialistas e autoritárias, a autonomia dos educandos é rebaixada; 5 . A autonomia (capacidade de organização) é importante, mas não esgota a questão. A autonomia deve ser compreendida como "possibilitadora" de desencadeamento de um processo mais profundo no sujeito (bio)ético, o da sua auto-organização (açōes e inter-retro-interaçōes). Assim, a autonomia pode contribuir (exocausalidade) para a auto-organização, mas somente a auto-organização, como processo endógeno de organização-desordem-reorganização, de homeostase e autopoiese, poderá produzir, pelo próprio sujeito (a partir da inter-retro-ação autonomia-dependência), essa consciência bioética.

\section{REFERÊNCIAS}

1. Pereira Jr A. O Problema da Auto-Determinação na Filosofia da Natureza [dissertação]. Belo Horizonte (MG): Universidade Federal de Minas Gerais; 1986.

2. Pereira Jr A, Pereira MAO. Teoria da auto-organização: uma introdução e possível aplicação nas ciências da saúde. Simbio-Logias Rev Eletrônica Educação Filosofia Nutri. 2010;3(5):102-114.

3. Maturana H, Varela F. Autopoiesis and Cognition. Boston Studies Philosophy of Science. Boston: Reidel. 1980;(42). DOI: http://dx.doi. org/10.1007/978-94-009-8947-4 13

4. Debrun MA. Ideia de Auto-Organização. In: Debrun M, Gonzalez MEQ, Pessoa Jr O, organizadores. Auto-Organização: estudos interdisciplinares. Campinas (SP): CLE/UNICAMP. 1996;18:3-23.

5. Debrun MA. Dinâmica da Auto-Organização Primária. In: Debrun M, Gonzalez MEQ, Pessoa Jr O, organizadores. Auto-Organização: estudos interdisciplinares. Campinas (SP): CLE/UNICAMP. 1996; 18:25-59.

6. Morin E. Ciência com consciência. 13a ed. Rio de Janeiro: Bertrand; 2010. 350 p.

7. Morin E. A cabeça bem-feita: repensar a reforma, reformar o pensamento. 7a ed. Rio de Janeiro: Bertrand; 2002.128 p.

8. Morin E. Os sete saberes necessários à educação do futuro. 6a ed. São Paulo: Cortez/ Brasília: UNESCO; 2002.118 p.

9. Scheler M. Etica, nuevo ensayo de fundamentación de un personalismo ético. 3a ed. Madrid: Caparrós Editores; 2001.758 p.

10. Cória-Sabini MA, Oliveira VK. Construindo valores humanos na escola. 2a ed. Campinas (SP): Papirus; 2002.96 p.

11. Carreras L, Eijo P, Estany A, Gómes MT, Guich R, Mir V, Ojeda F, Planas T, Serratas MG. Como educar integrando valores: materiais, textos, recursos e técnicas. São Paulo: Loyola; 2006. 343 p.

12. Piaget J. O juízo moral na criança. 3a ed. São Paulo: Summus; 1994. 302 p.

13. La Taille Y. Limites: três dimensões educacionais. São Paulo: Ática; 2006. 151 p. 